\title{
Phase II study of sequential S-1 and cyclophosphamide therapy in patients with metastatic breast cancer
}

Keiko Yanai ${ }^{1,2}$, Takaaki Fujii, ${ }^{1,2^{*}}$ (D), Jun Horiguchi ${ }^{3}$, Yuko Nakazawa $^{1,2}$, Sasagu Kurozumi ${ }^{1,2,3}$, Sayaka Obayashi ${ }^{1,2}$, Reina Yajima ${ }^{1,2}$ and Ken Shirabe ${ }^{2}$

\begin{abstract}
Background: S-1 and cyclophosphamide (CPA) can be given orally, and their combination may have great potential for treating metastatic breast cancer (MBC). A phase I study of sequential S-1 and CPA therapy was conducted in patients with $\mathrm{MBC}$; the recommended doses that were determined for this regimen were $80 \mathrm{mg} / \mathrm{m}^{2} /$ day for S-1 and $100 \mathrm{mg} / \mathrm{m}^{2} /$ day for CPA. We then conducted a phase II study of this oral S-1 and CPA regimen.
\end{abstract}

Methods: This was a single-arm, open-label, single-center prospective phase II study to evaluate the efficacy of a sequential S-1 and CPA regimen for MBC. S-1 was administered orally $2 \times /$ day for 14 consecutive days, and then CPA was administered orally $2 \times /$ day for 14 consecutive days in a repeating 4-week cycle (S-1 for 2 weeks, CPA for 2 weeks). The primary endpoint was the overall response rate (ORR). Secondary endpoints included the overall survival (OS), progression-free survival (PFS), clinical benefit rate (CBR) and safety.

Results: Thirty-six patients were enrolled in this study. The overall response was complete response in $0(0 \%)$, partial response in 12 (33.3\%), stable disease in 12 (33.3\%), and progressive disease in 11 (30.1\%) patients. The ORR was 33.3\% (12/36). The CBR was 66.7\% (24/36). The median PFS was 9.5 months (95\%Cl: 7.8-12.6 months). The median OS was 20.2 months (95\% Cl: 15.0-25.4 months) Grade 3/4 adverse events included leukopenia in seven patients (19.4\%). Dose reductions because of adverse events occurred in 12 patients (33.3\%). There was no treatment-related mortality.

Conclusion: The combination of sequential therapy with S-1 and CPA was tolerable and had efficacy with good disease control. Sequential therapy with S-1 and CPA may be a feasible new treatment option for patients with MBC; however, further study is warranted to explore the efficacy of this therapy.

Trial registration: JRCT, JRCTs031180296. Registered 2 December 2019 - Retrospectively registered.

Keywords: Metastatic breast cancer, S-1, Cyclophosphamide

\footnotetext{
* Correspondence: ftakaaki@gunma-u.ac.jp

'Division of Breast and Endocrine Surgery, Department of General Surgical

Science, Graduate School of Medicine, Gunma University, Gunma, Japan

2Department of General Surgical Science, Graduate School of Medicine,

Gunma University, Gunma, Japan

Full list of author information is available at the end of the article
}

(c) The Author(s). 2020 Open Access This article is licensed under a Creative Commons Attribution 4.0 International License, which permits use, sharing, adaptation, distribution and reproduction in any medium or format, as long as you give appropriate credit to the original author(s) and the source, provide a link to the Creative Commons licence, and indicate if changes were made. The images or other third party material in this article are included in the article's Creative Commons licence, unless indicated otherwise in a credit line to the material. If material is not included in the article's Creative Commons licence and your intended use is not permitted by statutory regulation or exceeds the permitted use, you will need to obtain permission directly from the copyright holder. To view a copy of this licence, visit http://creativecommons.org/licenses/by/4.0/ The Creative Commons Public Domain Dedication waiver (http://creativecommons.org/publicdomain/zero/1.0/) applies to the data made available in this article, unless otherwise stated in a credit line to the data. 


\section{Background}

Metastatic breast cancer (MBC) is not yet curable. The current treatment strategies for patients with $\mathrm{MBC}$ simply prolong survival and improve or maintain the patient's quality of life (QOL) [1-4]. There is an increasing demand for effective regimens that have less adverse effects for MBC patients. Taxane- or anthracycline-based regimens are established cytotoxic agents for patients with $\mathrm{MBC}$, but the administration of taxane or anthracycline can cause serious adverse events (including myelosuppression, hair loss, nausea, edema, and peripheral neuropathy) that may affect patients' health-related quality of life (HRQOL) $[4,5]$. Less-toxic treatments that do not reduce the HRQOL are needed for the management of $\mathrm{MBC}$.

Orally administered drugs are generally more convenient to use than intravenous drugs $[4,6]$. The oral fluorouracil derivatives S-1 is widely used in Japan [3, 4, 7-10]. S-1 is a combination of tegafur (a prodrug of 5fluorouracil), gimeracil (an inhibitor of dihydropyrimidine dehydrogenase, the rate-limiting enzyme in the catabolism of 5-fluorouracil), and potassium oxonate (an inhibitor of orotate phosphoribosyltransferase, which suppresses the gastrointestinal toxicity of 5-fluorouracil) in the molar ratio of 1.0: 0.4: $1.0[2,3]$. S-1 treatment resulted in an overall response rate of $41.7 \%$ in a phase II trials of patient with breast cancer in Japan [8].

A recent randomized phase III study (the SELECT BC trial) indicated that as a first-line treatment for $\mathrm{MBC}, \mathrm{S}-1$ is noninferior to taxane with respect to overall survival [4]. We also reported that the combination of S-1 and trastuzumab was tolerable and had excellent efficacy with good response and disease control for HER2-positive metastatic breast cancer [3]. Regarding adverse events, S-1 has shown low incidences of myelosuppression, nausea, vomiting, alopecia, and peripheral neuropathy $[2,3]$. Thus, S-1 was demonstrated to have high efficacy for MBC with a low incidence of adverse events [4,8].

Cyclophosphamide (CPA) is one of the oldest drugs used in oncology; it was the first available drug in oral formulations for the management of MBC [11-13]. CPA is typically used as a component of combination regimens such as AC (doxorubicin and CPA) and fluoropyrimidine-based combination regimens including CMF (CPA, methotrexate, and 5-fluorouracil [5-FU]) [14]. The use of oral agents can make a significant contribution to a patient's QOL. Several studies reported that oral combination regimens of CPA plus UFT (tegafur/uracil) or capecitabine is effective with well-tolerated toxicities in patients with MBC [15-17]. However, no data evaluating the efficacy of S-1 plus CPA therapy for $\mathrm{MBC}$ is available in the existing literature. We thus conducted a phase I study of sequential S-1 and CPA therapy to determine the dose-limiting toxicities (DLTs) and recommended doses (RDs) in patients with MBC [18], and we reported that sequential therapy with S-1 and CPA could be safely and effectively used for the treatment of $\mathrm{MBC}$; the RDs determined for this regimen were $80 \mathrm{mg} / \mathrm{m}^{2} /$ day for $\mathrm{S}-1$ and $100 \mathrm{mg} / \mathrm{m}^{2} /$ day for CPA [18]. We then performed a phase II trial to verify the clinical efficacy of sequential S-1 and CPA for MBC, and we report the results as follows.

\section{Methods}

\section{Study design and patients}

We conducted a single arm, open-label, single center phase II trial to evaluate the efficacy of a sequential S-1 and CPA regimen for MBC. Women aged 20-75 years old with a histological diagnosis of $\mathrm{MBC}$ were considered eligible for the study. Eligibility required a measurable tumor based on the RECIST criteria; an Eastern Cooperative Oncology Group performance status of 0 or 1 ; a body surface area $>1.25$; expected survival $>3$ months; adequate organ function defined as a leukocyte count $3500-12,000 / \mathrm{mm}^{3}$ (or neutrophil count $>2000 / \mathrm{mm}^{3}$ ), platelet count > $100,000 / \mathrm{mm}^{3}$, hemoglobin $>9 \mathrm{~g} / \mathrm{dl}$, serum ALT and AST level less than the upper level of normal in each institution $\times 2.5$, serum total bilirubin $<1.5 \mathrm{mg} / \mathrm{dl}$, and serum creatinine $<1.2 \mathrm{mg} / \mathrm{dl}$ (or creatinine clearance $>50 \mathrm{ml} / \mathrm{min}$ ); and the resolution of all toxicities from prior therapy. All patients provided written informed consent to participate in this study. The sample size was estimated to be approximately 40 patients, without any calculations based on statistical assumptions from previous phase I/II studies [10-15].

The exclusion criteria included symptomatic central nervous system metastases, active systemic infectious disease, clinically significant cardiovascular impairment, serious concomitant illness, pregnancy, breast feeding, a history of other cancers with a disease-free interval of $\leq 5$ years, patients who had received trastuzumabcontaining therapy within the prior 4 weeks, those who were receiving 5-FU-containing therapy, flucytosine, or pentostatin, and those who had recurrent disease within 1 year after having received 5-FU-containing therapy or CPA. From November 2007 to December 2018, a total of 36 patients were enrolled in this study. The demographic characteristics of the patients are summarized in Table 1 . The study was carried out at Gunma University, Japan. The study protocol was approved by our Ethics Committee.

\section{Treatment procedure}

According to the RDs determined by our phase I study [18], S-1 $80 \mathrm{mg} / \mathrm{m}^{2} /$ day divided twice a day orally for 14 consecutive days, and then CPA $100 \mathrm{mg} / \mathrm{m}^{2} /$ day divided twice a day orally for 14 consecutive days in a repeating 4-week cycle (S-1 for 2 weeks, CPA for 2 weeks). This 
Table 1 Patients' characteristics and clinicopathological features

\begin{tabular}{ll}
\hline Age median (range), (y.o.) & $\mathbf{5 0 ~ ( 3 3 - 7 4 )}$ \\
\hline Metastatic de-novo or recurrent, $(\mathrm{n})$ & $10(27.8 \%)$ \\
Metastatic de-novo & $26(72.2 \%)$ \\
Metastatic recurrent & \\
Subtype & $29(80.6 \%)$ \\
$\quad$ Luminal & $7(19.4 \%)$ \\
Triple negative & \\
Number of previous chemotherapy regimens, (n) & $22(61.1 \%)$ \\
0 & $10(27.8 \%)$ \\
1 & $2(5.6 \%)$ \\
2 & $2(5.6 \%)$ \\
$\geqq 3$ & $26(72.2 \%)$ \\
Previous endocrine therapy, (n) & \\
Metastatic sites, (n) & $23(63.9 \%)$ \\
Visceral & $13(36.1 \%)$ \\
Non-visceral &
\end{tabular}

regimen was continued until the occurrence of (1) progressive disease (PD) as assessed by the investigator using RECIST criteria, or (2) the appearance of unmanageable toxicity, or (3) the patient's withdrawal of consent. Any concomitant medication could be given at the discretion of the investigator if it was considered necessary for the patient's welfare and was not expected to interfere with the evaluation of the study treatment. Other antitumor therapies were not permitted.

\section{Assessments}

The primary endpoint was the antitumor activity of the sequential S-1 and CPA therapy as assessed by the overall response rate (ORR) based on the RECIST criteria. The secondary endpoints included the patients' overall survival (OS) and progression-free survival (PFS), the clinical benefit rate (CBR), and the regimen's safety. Routine tumor assessments based on the RECIST criteria were performed 1 month after the first dose and then every month during the treatment period. The ORR was defined as the proportion of patients with a complete response (CR) or a partial response (PR) among all patients. The CBR was defined as the proportion of patients with a CR or PR or stable disease (SD) continuing $>4$ weeks (28 days). CR and PR required confirmation at $\geq 4$ weeks after first being reported. The Kaplan-Meier approach was used to estimate the median PFS and OS values.

Treatment-related adverse events were evaluated according to the Common Terminology Criteria for Adverse Events, ver. 3.0 and 4.0. There was a protocol amendment that changed the evaluation from version 3 to 4 in the middle of the trial. The incidence of adverse events was calculated according to grade. Hematology and biochemistry assessments, physical examinations, and periodic measurements of vital signs were performed before the start of each treatment cycle.

\section{Results}

The patient's characteristics

From November 2007 to December 2018, a total of 36 patients were enrolled in this study at Gunma University, Japan. The characteristics of patients are summarized in Table 1 . Of the 36 patients, 26 had metastatic recurrent cancer, and 10 patients had metastatic denovo breast cancer. The median age was 50 years (range 33-74). Twenty-nine patients were hormonal receptor (HR)-positive (ER+ and/or PgR+). Seven patients had triple-negative tumors. Visceral metastasis including liver and lung metastases was observed in 23 cases (63.9\%), and non-visceral metastasis including bone and lymph nodes metastases was observed in 13 cases (36.1\%). Ten patients had received one line of chemotherapy before registration; 2 other patients had received 2 lines of chemotherapy, and another 2 patients had received $\geq 3$ of chemotherapy. Thus, 22 patients (61.1\%) were receiving sequential $\mathrm{S}-1$ and CPA treatment as their first-line chemotherapy. Twenty-six patients received endocrine therapy for $\mathrm{MBC}$ before registration in this study.

\section{Tumor responses and survival}

The overall response was a CR in $0(0 \%)$, a PR in 12 (33.3\%), SD in 12 (33.3\%), and PD in 11 (33.3\%) patients; one patient was non-evaluable for response. The ORR was $33.3 \%(12 / 36)$, and the CBR was $66.7 \%(24 / 36)$. The median PFS in this patient population was 9.5 months (95\%CI: 7.8-12.6 months), and the median OS was 20.2 months (95\%CI: 15.0-25.4 months) (Fig. 1).

We divided the patients into two groups based on a) metastatic de-novo versus metastatic recurrent; b) with no prior chemotherapy versus those with one or more of them; c) with visceral metastasis versus non-visceral metastasis; d) luminal type versus triple negative breast cancer (Table 2a-d). There were no significant differences between patients with and without prior chemotherapy $(p=0.784)$, visceral metastasis $(p=0.254)$ or subtype $(p=0.609)$; however, the PFS was significantly shorter in patients with metastatic de-novo disease than that in patients with metastatic recurrent disease $(p=0.007)$ (Fig. 2a-d).

\section{Safety}

All patients were assessed for toxicities during the treatment cycles. The adverse events are shown in Table 3. Regarding hematologic toxicity, leukopenia occurred in seven (19.4\%) patients, anemia in one (2.8\%), and 
a.

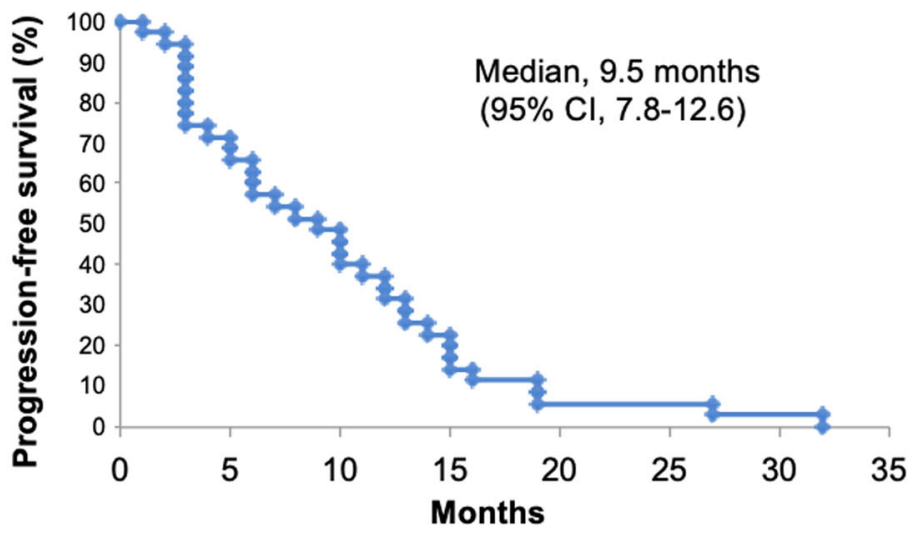

b.

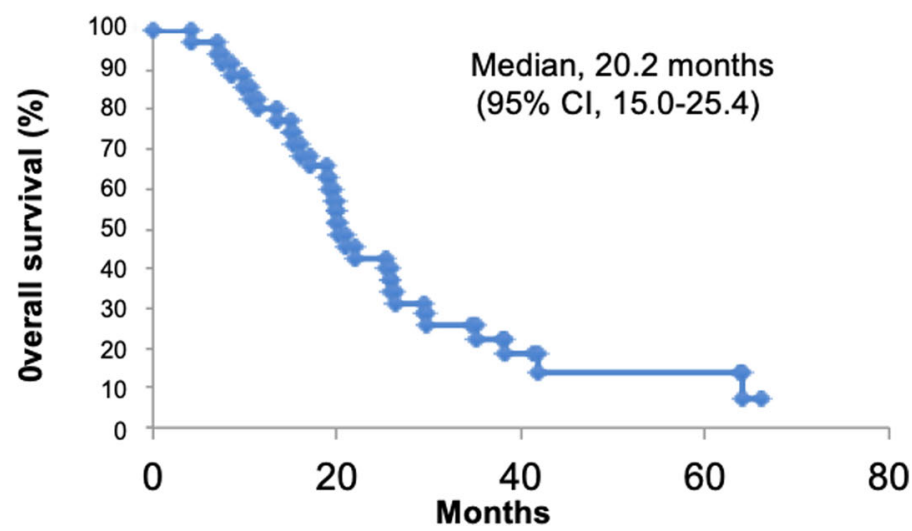

Fig. 1 Kaplan-Meier estimates of the progression-free survival (PFS) and overall survival (OS). a The median PFS was 9.5 months (95\% Cl: 7.8-12.6 months). b The median OS was 20.2 months (95\% Cl: 15.0-25.4 months)

thrombocytopenia in three (8.3\%). Five (13.9\%) patients had grade 3 leukopenia, but no patients had grade 4 hematologic toxicity. Grade 3/4 adverse events included leukopenia in 7 patients each (19.4\%). With regard to non-hematological toxicities, the most common adverse event was fatigue. One patient had nasolacrimal duct obstruction. Dose reductions because of adverse events occurred in 12 patients (33.3\%). Treatment was discontinued because of sepsis in one patient (2.8\%). There was no treatment-related mortality.

\section{Discussion}

The goals of the current treatment for patients with $\mathrm{MBC}$ are to prolong survival and improve or maintain an adequate QOL and HRQOL [1-4]. Thus, less-toxic treatments should be chosen as long as the treatment can control the disease progression [9]. Compared to intravenous chemotherapy for patients with $\mathrm{MBC}$, the use of oral chemotherapy affords a better QOL $[4,6]$. S1 chemotherapy, which is often used in Japan, is composed of oral fluorouracil derivatives. In the SELE CT BC trials, S-1 was shown to be noninferior to taxane with respect to $O S$ and better than taxane with regard to HRQOL as a first-line treatment for patients with MBC [4]. In addition, 5-FU demonstrated a synergistic antitumor effect in combination with CPA in experimental studies and in a phase II trial [14, 19-22], but it also had a significantly higher rate of toxicity $[21,22]$.

The present study's ORR and CBR were 33.3 and 66.7\%, respectively, with 9.5 months as the median PFS of and 20.2 months as median OS. The treatment was well tolerated. The most common toxicity was leukopenia, which was observed in $19.4 \%$ of cases. Previous phase II studies using standard metronomic chemotherapy revealed that leukopenia was observed in $51 \%$ or $31 \%[12,13]$ and thrombocytopenia was observed in 5 and $8 \%[12,13]$, which is considered to be same to the toxicity of this study. These results strongly suggest that sequential S-1 and CPA therapy is an effective treatment option for $\mathrm{MBC}$, with a manageable toxicity profile. In 
Table 2 Patients' characteristics and clinicopathological feature in subgroup analysis.

a) Metastatic de-novo versus metastatic recurrent

Metastatic recurrent $(n=26)$

Age median (range), (y.o.)

Subtype

$$
\begin{aligned}
& \text { Luminal } \\
& \text { Triple negative }
\end{aligned}
$$

Number of previous chemotherapy regimens, ( $n$ )

0
1
2
$\geqq 3$

Previous endocrine therapy, (n)

Metastatic sites, (n)

Visceral

Non-visceral

b) No prior chemotherapy $(\mathrm{CT})$ versus after chemotherapy.

Age median (range), (y.o.)

Metastatic de-novo or recurrent, (n)

Metastatic de-novo

Subtype

Luminal

Triple negative

Previous endocrine therapy, (n)

Metastatic sites, (n)

\section{Visceral \\ Non-visceral}

c) Visceral metastasis versus non-visceral metastasis.

Age median (range), (y.o.)
Metastatic de-novo or recurrent, (n)
Metastatic de-novo
Metastatic recurrent
Subtype
Luminal
Triple negative

Number of previous chemotherapy regimens, (n)

$$
\begin{aligned}
& 0 \\
& 1 \\
& 2 \\
& \geqq 3
\end{aligned}
$$

Previous endocrine therapy, (n)

d) Luminal type versus triple negative breast cancer.

No primary $C T(n=22)$

Visceral metastasis $(n=23)$

$51.5(33-73)$

$\begin{array}{ll}\text { Metastatic de-novo }(n=10) & P \text { value } \\ 49(35-64) & 0.344 \\ & 0.079 \\ 10(100 \%) & \\ 0(0 \%) & \end{array}$

$17(65.4 \%) \quad 5(50.0 \%)$

$6(27.3 \%) \quad 4(40.0 \%)$

$1(3.8 \%) \quad 1(10.0 \%)$

$2(7.7 \%) \quad 0(0 \%)$

$16(61.5 \%) \quad 10(100 \%)$

0.021

0.473

$16(61.5 \%) \quad 7(70.0 \%)$

$10(27.8 \%) \quad 3(30.0 \%)$

After $C T(n=14) \quad \quad P$ value

$\begin{array}{ll}51(34-74) & 47(33-73) \\ & 0.243 \\ & 0.318\end{array}$

$5(22.7 \%) \quad 5(35.7 \%)$

$17(77.3 \%) \quad 9(64.3 \%)$

0.433

$17(77.3 \%) \quad 12(85.7 \%)$

$5(22.7 \%) \quad 2(14.3 \%)$

$16(72.7 \%) \quad 10(71.4 \%) \quad 0.611$

$15(68.2 \%) \quad 8(57.1 \%)$

$7(31.8 \%) \quad 6(42.9 \%)$

Non-visceral metastasis $(n=13) \quad P$ value

48 (34-74) $\quad 0.135$

0.473

$7(30.4 \%) \quad 3(23.1 \%)$

$16(69.6 \%) \quad 10(76.9 \%)$

0.499

$19(82.6 \%) \quad 10(76.9 \%)$

$4(17.4 \%) \quad 3(23.1 \%)$

0.920

$14(60.9 \%) \quad 8(61.5 \%)$

$7(30.4 \%) \quad 3(23.1 \%)$

$1(4.3 \%) \quad 1(7.7 \%)$

$1(4.3 \%) \quad 1(7.7 \%)$

$18(78.3 \%) \quad 8(61.5 \%)$

0.420

Luminal $(n=29)$
$\mathrm{TN}(n=7)$ 
Table 2 Patients' characteristics and clinicopathological feature in subgroup analysis. (Continued)

\begin{tabular}{|c|c|c|c|}
\hline Age median (range), (y.o.) & $50(33-74)$ & $58(36-73)$ & 0.219 \\
\hline Metastatic de-novo or recurrent, (n) & & & 0.079 \\
\hline Metastatic de-novo & $10(22.7 \%)$ & $0(35.7 \%)$ & \\
\hline Metastatic recurrent & 19 (77.3\%) & $7(64.3 \%)$ & \\
\hline Number of previous chemotherapy regimens, (n) & & & 0.773 \\
\hline 0 & $17(60.9 \%)$ & $5(61.5 \%)$ & \\
\hline 1 & $8(30.4 \%)$ & $2(23.1 \%)$ & \\
\hline 2 & $2(4.3 \%)$ & $0(7.7 \%)$ & \\
\hline$\geqq 3$ & $2(4.3 \%)$ & $0(7.7 \%)$ & \\
\hline Metastatic sites, (n) & & & 0.499 \\
\hline Visceral & $19(68.2 \%)$ & $4(57.1 \%)$ & \\
\hline \multirow[t]{2}{*}{ Non-visceral } & $10(31.8 \%)$ & $3(42.9 \%)$ & \\
\hline & Metastatic recurrent $(n=19)$ & Metastatic de-novo $(n=10)$ & $P$ value \\
\hline Age median (range), (y.o.) & $50(33-74)$ & $49(35-64)$ & 0.618 \\
\hline Number of previous chemotherapy regimens, (n) & & & 0.510 \\
\hline 0 & $12(65.4 \%)$ & $5(50.0 \%)$ & \\
\hline 1 & $4(27.3 \%)$ & $4(40.0 \%)$ & \\
\hline 2 & $1(3.8 \%)$ & $1(10.0 \%)$ & \\
\hline$\geqq 3$ & $2(7.7 \%)$ & $0(0 \%)$ & \\
\hline Previous endocrine therapy, (n) & $15(61.5 \%)$ & $10(100 \%)$ & 0.163 \\
\hline Metastatic sites, (n) & & & 0.522 \\
\hline Visceral & $12(61.5 \%)$ & $7(70.0 \%)$ & \\
\hline Non-visceral & $7(27.8 \%)$ & $3(30.0 \%)$ & \\
\hline
\end{tabular}

the SELECT BC trial, the median time to failure (TTF) was 8.0 months in the group administered $\mathrm{S}-1$ as the first-line chemotherapy [4]. Regarding capecitabine+ CPA combination treatment, two phase II studies have already reported this regimen's efficacy $[15,16]$. The ORRs of 35.6 and $30.3 \%$ in those studies are consistent with our present study. The median PFS in those studies were 6.6 months and 5.2 months, respectively $[15,16]$.

There is no meaningful biomarker for the efficacy of S-1/CPA. We conducted the comparison of the data obtained in certain subgroups of patients in order to find out patients with better chances of having a good clinical response. We divided the patients into two groups based on a) metastatic de-novo versus metastatic recurrent; b) with no prior chemotherapy versus those with one or more of them; c) with visceral metastasis versus nonvisceral metastasis; d) luminal type versus triple negative breast cancer. There were no significant differences between patients with and without prior chemotherapy, visceral metastasis or subtype, however, the PFS was significantly shorter in patients with metastatic de-novo than that in patients with metastatic recurrent, suggesting that this therapy may show superior effect in patients with metastatic recurrent. The mechanism is unknown, however, all patients with metastatic de-novo were luminal type. Further study should be done to evaluate how metastatic de-novo breast cancer influence the antitumor effect of S-1/CPA in large number of patients.

All-grade leukopenia was observed in $19.4 \%$ of our present series, and one patient was unable to continue the therapy. In the SELECT BC trial, all-grade leukopenia was observed in $43 \%$ of the $\mathrm{S}-1$ group [4]. Of our 36 patients with $\mathrm{MBC}$, grade 3 leukopenia was observed in $13.9 \%$, as one of the most common adverse events in this regimen. Adverse events such as hair loss, peripheral neuropathy, gastrointestinal toxicity and edema - which are commonly observed in patients with taxane or anthracycline regimens [23] - were not observed in our study. The benefit of avoiding hair loss is of particular concern from the patients' perspective [24]. Approximately 10-20\% of patients who received S-1 developed lacrimal drainage obstruction or stenosis [25, $26]$. In the present trial, only one $(2.8 \%)$ patient developed lacrimal drainage obstruction. In light of these results, we suggest that this sequential S-1 and CPA therapy is a feasible and tolerable regimen in terms of both efficacy and safety.

This study has potential limitations, the major one being the small number of cases $(n=36)$ and the inclusion of a single center. However, this is the first prospective 
a.

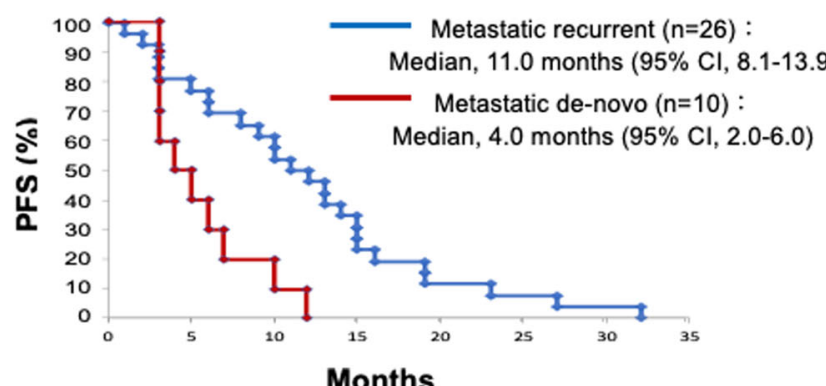

b.

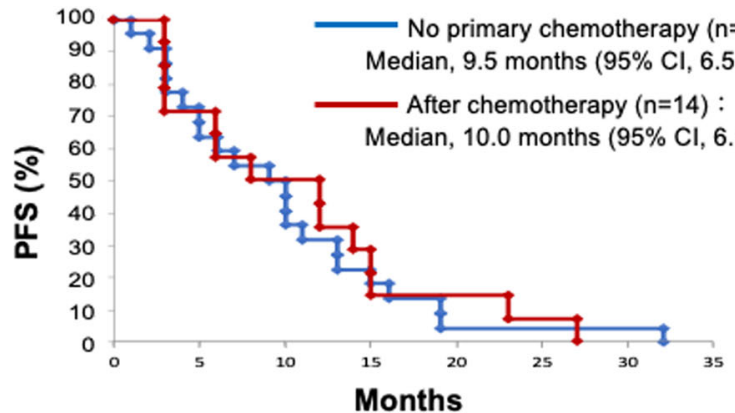

C.
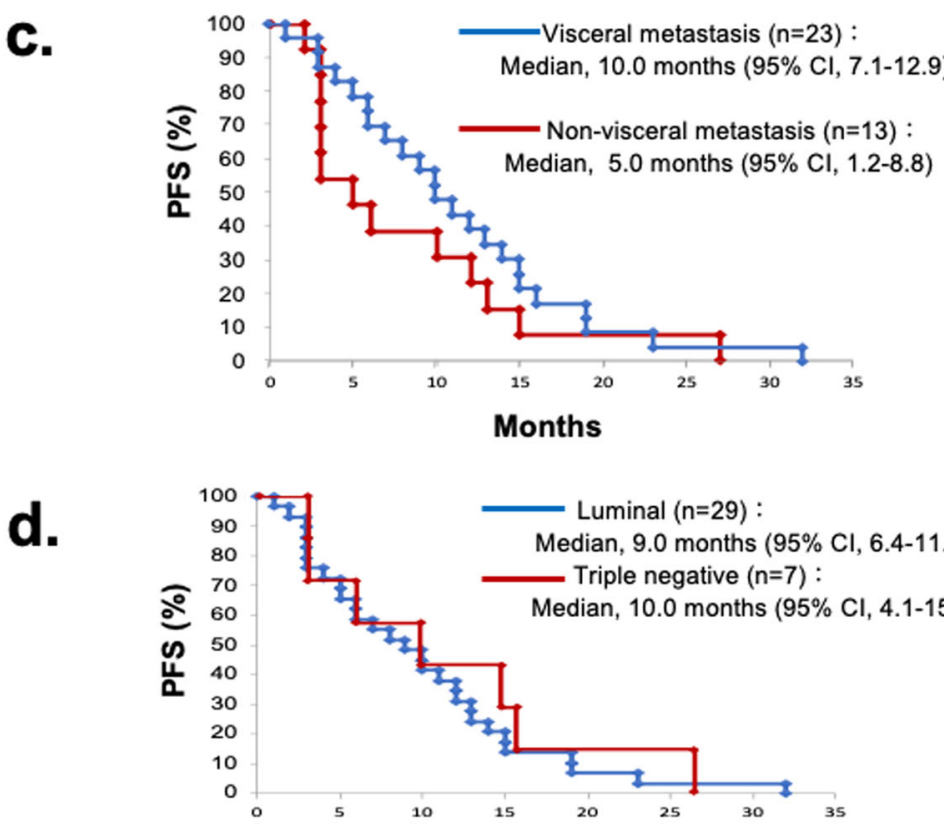

Months

Fig. 2 Kaplan-Meier estimates of the progression-free survival (PFS) of subgroup analysis. a Metastatic de-novo versus metastatic recurrent. The median PFS was 11.0 months (95\%Cl: 8.1-13.9 months) in patients with metastatic recurrent, and the median PFS was 4.0 months (95\%Cl: 2.0-6.0 months) in patients with metastatic de-novo. b No prior chemotherapy versus after chemotherapy. The median PFS was 9.5 months (95\%Cl: $6.5-$ 12.5 months) in patients with no primary chemotherapy, and the median PFS was 10.5 months (95\%Cl: 6.1-13.9 months) in patients after chemotherapy. c Visceral metastasis versus non-visceral metastasis. The median PFS was 10.0 months (95\%Cl: $7.1-12.9$ months) in patients with visceral metastasis, and the median PFS was 5.0 months (95\%Cl: 1.2-8.8 months) in patients without visceral metastasis. $\mathbf{d}$ Luminal type versus triple negative breast cancer. The median PFS was 9.0 months (95\%Cl: 6.4-11.6 months) in patients with luminal type, and the median PFS was 10.0 months (95\% Cl: $4.1-15.9$ months) in patients without triple negative breast cancer. There were no significant differences between patients with and without prior chemotherapy $(p=0.784)$, visceral metastasis $(p=0.254)$ or subtype $(p=0.609)$, however, the PFS was significantly shorter in patients with metastatic de-novo than that in patients with metastatic recurrent $(p=0.007)$ 
Table 3 The treatment-related any-grade adverse events and grade 3/4 adverse events

\begin{tabular}{lll}
\hline Adverse Events, $(\mathbf{n})$ & All Grade & Grade 3/4 \\
\hline Leukopenia & $7(19.4 \%)$ & $5(13.9 \%)$ \\
Anemia & $1(2.8 \%)$ & $1(2.8 \%)$ \\
Thrombocytopenia & $3(8.3 \%)$ & $1(2.8 \%)$ \\
Fatigue & $3(8.3 \%)$ & 0 \\
Nasolacrimal duct obstruction & $1(2.8 \%)$ & 0 \\
Sepsis & $1(2.8 \%)$ & $1(2.8 \%)$ \\
\hline
\end{tabular}

clinical trial to evaluate the efficacy of sequential therapy with S-1 and CPA for metastatic breast cancer. Additional research is needed to explore the efficacy of this therapy in larger numbers of patients to confirm the effects and safety profile of sequential therapy with S-1 and CPA.

\section{Conclusions}

The combination of sequential therapy with S-1 and CPA was tolerable and had efficacy with good disease control in this study. Sequential therapy with S-1 and CPA may be a feasible new treatment option for patients with $\mathrm{MBC}$. Further study is warranted to explore the efficacy of sequential therapy with S-1 and CPA, especially considering this is a small, open-label, single center trial with no formal hypothesis testing.

\section{Abbreviations \\ CBR: Clinical benefit rate; CPA: Cyclophosphamide; CR: Complete response; DLTs: Dose-limiting toxicities; HRQOL: Health-related quality of life; MBC: Metastatic breast cancer; ORR: Overall response rate; OS: Overall survival; PD: Progressive disease; PFS: Progression-free survival; PR: Partial response; QOL: Quality of life; RDs: Recommended doses; SD: Stable disease; TTF: Time to failure}

\section{Acknowledgements}

The authors would like to thank Ms. Fumie Takada and Ms. Harumi Kanai for their secretarial assistance. FT and HK belong to Department of General Surgical Science, Gunma University Graduate School of Medicine. Maebashi, Gunma, 371-8511 Japan.

\section{Authors' contributions}

TF and KY analysed data and wrote the initial draft of the manuscript. KY, TF, $J H, Y N, S K, S O$ and RY collected data and were involved in the initial study conception and design. TF and KS interpreted the results and were involved in drafting the work and revising it critically for important intellectual content. TF approved the final version to be published. All authors have read and approved the final manuscript.

\section{Funding}

Supported by Grants-in-Aid from the Japanese Ministry of Education, Culture, Sports, Science and Technology (T.F.).

\section{Availability of data and materials}

The datasets used and/or analysed during the current study are available from the corresponding author on reasonable request.

\section{Ethics approval and consent to participate}

This study was conducted in accordance with the Declaration of Helsinki, and the protocol was approved by the Clinical Ethics Committee of Gunma University. Written consent was obtained from all patients for the use of their records and imaging in future studies.

\section{Consent for publication}

Not applicable.

\section{Competing interests}

The authors declare that they have no competing interests.

\section{Author details}

${ }^{1}$ Division of Breast and Endocrine Surgery, Department of General Surgical Science, Graduate School of Medicine, Gunma University, Gunma, Japan. ${ }^{2}$ Department of General Surgical Science, Graduate School of Medicine, Gunma University, Gunma, Japan. ${ }^{3}$ Breast Surgery, International University of Health and Welfare, Chiba, Japan.

Received: 15 April 2020 Accepted: 21 October 2020

Published online: 06 November 2020

\section{References}

1. Hortobagyi GN. Treatment of breast cancer. N Engl J Med. 1998;14:974-84.

2. Suzuki Y, Ogiya R, Oshitanai R, Terao M, Terada M, Morioka T, Tsuda B, Niikura N, Okamura T, Saito Y, Tokuda Y. Feasibility and pharmacokinetics of combined therapy with S-1 and trastuzumab in patients with human epidermal growth factor receptor 2-positive metastatic or recurrent breast cancer. Int J Clin Oncol. 2014;19:274-9.

3. Fujii T, Horiguchi J, Yanagita Y, Koibuchi Y, Ikeda F, Uchida N, Kimura M, GUNMA BREAST CLINICAL CONFERENCE STUDY GROUP (GBCCSG). Phase ॥ study of S-1 plus trastuzumab for HER2-positive metastatic breast cancer (GBCCSG-01). Anticancer Res. 2018;38:905-9.

4. Takashima T, Mukai H, Hara F, Matsubara N, Saito T, Takano T, Park Y, Toyama T, Hozumi Y, Tsurutani J, Imoto S, Watanabe T, Sagara Y, Nishimura R, Shimozuma K. Ohashi $Y$, for the SELECT BC study group: Taxanes versus S-1 as the first-line chemotherapy for metastatic breast cancer (SELECT BC): an open-label, noninferiority, randomized phase 3 trial. Lancet Oncol. 2016;17:90-8.

5. Shimozuma K, Ohashi Y, Aranishi T, Morita S, Kuroi K, Ohsumi S, Makino H, Katsumata N, Kuranami M, Suemasu K, Watanabe T, Hausheer FH. Taxaneinduced peripheral neuropathy and health-related quality of life in postoperative breast cancer patients undergoing adjuvant chemotherapy: NSAS BC 02, a randomized clinical trial. Support Care Cancer. 2012;20:3355-64.

6. Sparreboom A, de Jonge MJ, Verweij J. The use of oral cytotoxic and cytostatic drugs in cancer treatment. Eur J Cancer. 2002;38:18-22.

7. Ishiguro H, Saji S, Nomura S, Tanaka S, Ueno T, Onoue M, Iwata H, Yamanaka T, Sasaki Y, Toi M. A phase I/II pharmacokinetics/ pharmacodynamics study of irinotecan combined with S-1 for recurrent/ metastatic breast cancer in patients with selected UGT1A1 genotypes (the JBCRG-M01 study). Cancer Med. 2017:6:2909-17.

8. Saek T, Takashima S, Sano M, Horikoshi N, Miura S, Shimizu S, Morimoto K, Kimura M, Aoyama H, Ota J, Noguchi S, Taguchi T. A phase II study of S-1 in patients with metastatic breast cancer - a Japanese trial by the S-1 cooperative study group, Breast Cancer Working Group. Breast Cancer. 2004; 11:194-202.

9. Takashima T, Nakayama T, Yoshidome K, Kawajiri H, Kamigaki S, Tsurutani J, Arai T, Ito T, Komoike Y, Doi T, Masuda N, Miyauchi K, Miyoshi Y, Aakamoto J, Morita S, Taguchi T. Phase II study of S-1 in combination with trastuzumab for HER2-positive metastatic breast cancer. Anticancer Res. 2014:34:3583-8.

10. Shigekawa T, Osaki A, Sekine H, Sato N, Kanbayashi C, Sano H, Takeuchi H, Udea S, Nakamiya N, Sugitani I, Sugiyama M, Shimada H, Hirokawa E, Takahashi T, Saeki T. Safety and feasibility of adjuvant chemotherapy with S1 in Japanese breast cancer patients after primary systemic chemotherapy: a feasibility study. BMC Cancer. 2015;15:253.

11. Kurtz JE, Deplanque G, Borel G, Mathelin C, Prévost G, Poulin G, Barats JC, Bergerat JP, Chapelle-Marcillac I, Bardonnet M, Dufour P. Dose-finding study of oral idarubicin and cyclophosphamide in first-line treatment of elderly patients with metastatic breast cancer. Ann Oncol. 2000;11:229-30.

12. Colleoni M, Rocca A, Sandri TM, Zorzino L, Masci G, Nolé F, Peruzzotti G, Robertson C, Orlando L, Cinieri S, de Braud F, Viale G, Goldhirsch A. Lowdose oral methotrexate and cyclophosphamide in metastatic breast cancer: antitumor activity and correlation with vascular endothelial growth factor levels. Ann Oncol. 2002;13:73-80.

13. Gebbia V, Boussen $H$, Valerio MR. Oral metronomic cyclophosphamide with and without methotrexate as palliative treatment for patients with metastatic breast carcinoma. Anticancer Res. 2012;32:529-36. 
14. Ohno S, Mitsuyama S, Tamura K, Nishimura R, Tanaka M, Hamada Y, Kurok S, The KYUSHU BREAST CANCER STUDY GROUP. Dosage of capecitabine and cyclophosphamide combination therapy in patients with metastatic breast cancer. Anticancer Res. 2007:27:1009-14.

15. Tanaka M, Takamatsu Y, Anan K, Ohno S, Nishimura R, Yamamoto Y, Masuda N, Mitsuyama S, Tamura K, KYUSHU BREAST CANCER STUDY GROUP. Oral combination chemotherapy with capecitabine and cyclophosphamide in patients with metastatic breast cancer: a phase II study. Anti-Cancer Drugs. 2010;21:453-8.

16. Wang Z, Lu J, Leaw S, Hong X, Wang J, Shao Z, Hu X. An all-oral combination of metronomic cyclophosphamide plus capecitabine in patients with anthracycline- and taxane-pretreated metastatic breast cancer: a phase II study. Cancer Chemother Pharmacol. 2012;69:515-22.

17. Ogawa Y, Ishikawa T, Chung SH, Ikeda K, Takashima T, Onoda N, Nakata B, Nishiguchi Y, Hirakawa K. Oral UFT and cyclophosphamide combination chemotherapy for metastatic breast cancer. Anticancer Res. 2003;23:3453-7.

18. Horiguchi J, Takata D, Rokutanda N, Nagaoka R, Tokiniwa H, Odawara H, Kikuchi M, Sato A, Takeyoshi I. Phase I study of sequential S-1 and cyclophosphamide therapy in patients with metastatic breast cancer. Gan To Kagaku Ryoho. 2013;40:1175-80.

19. Munoz R, Man S, Shaked Y, Lee CR, Wong J, Francia G, Kerbel RS. Highly efficacious nontoxic preclinical treatment for advanced metastatic breast cancer using combination oral UFT-cyclphosphamide metronomic chemotherapy. Cancer Res. 2006;66:3386-91.

20. Yonekura Y, Basaki Y, Chikahisa L, Okabe S, Hashimoto A, Miyadera K, Wierzba K, Yamada Y. UFT and its metabolites inhibit the angiogenesis induced by murine renal cell carcinoma, as determined by a dorsal air sac assay in mice. Clin Cancer Res. 1999;5:2185-91.

21. Yoshimoto M, Tada K, Tokudome N. Kutomi Gm Tanabe M, Goto T, Nishimura S, Makita M, Kasumi F: the potential for oral combination chemotherapy of 5'deozy-5-fluorouridine, a 5-FU prodrug, and cyclophosphamide for metastatic breast cancer. Br J Cancer. 2003:89:1627-32.

22. Tominaga T, Koyama H, Toge T, Miura S, Sucimachi K, Yamaguchi S, Hirata K, Monden Y, Nomura Y, Toi M, Kimijima I, Noguchi S, Sonoo H, Asaishi K, Ikeda T, Morimoto T, Ota J, Ohashi Y, Abe O. Randomized controlled trial comparing oral doxifluridine plus oral cyclophosphamide with doxifluridine alone in women with node-positive breast cancer after primary surgery. J Clin Oncol. 2003;21:991-8.

23. Ghersi D, Wilcken N, Simes RJ. A systematic review of taxane-containing regimens for metastatic breast cancer. Br J Cancer. 2005;93:293-301.

24. Nozawa K, Shimizu C, Kakimoto M, Mizota Y, Yamamoto S, Takahashi Y, Ito A, Izumi H, Fujiwara Y. Quantitative assessment of appearance changes and related distress in cancer patients. Psychooncology. 2013;22:2140-7.

25. Sasaki T, Miyashita H, Miyanaga T, Yamamoto K, Sugiyama K. Dacryoendoscopic observation and incidence of canalicular obstruction/ stenosis associated with S-1, an oral anticancer drug. Jpn J Ophthalmol. 2012;56:214-8.

26. Kim N, Park C, Park DJ, Kim HH, Kim S, Kim YJ, Lee JS, Bang YJ, Khwarg SI, Choung $\mathrm{H}$, Lee MJ, Lee KW. Lacrimal drainage obstruction in gastric cancer patients receiving S-1 chemotherapy. Ann Oncol. 2012;23:2065-71.

\section{Publisher's Note}

Springer Nature remains neutral with regard to jurisdictional claims in published maps and institutional affiliations.

\section{Ready to submit your research? Choose BMC and benefit from:}

- fast, convenient online submission

- thorough peer review by experienced researchers in your field

- rapid publication on acceptance

- support for research data, including large and complex data types

- gold Open Access which fosters wider collaboration and increased citations

- maximum visibility for your research: over $100 \mathrm{M}$ website views per year

At BMC, research is always in progress.

Learn more biomedcentral.com/submissions 